\title{
Fracability Evaluation Method and Influencing Factors of the Tight Sandstone Reservoir
}

\author{
Jiageng Liu, ${ }^{1}$ Lisha $Q u,{ }^{1}$ Ziyi Song, ${ }^{2}$ Jing Li $\mathbb{D},{ }^{1}$ Chen Liu, ${ }^{1}$ Yongcun Feng $\mathbb{D},{ }^{3}$ \\ and Haihang Sun ${ }^{4}$ \\ ${ }^{1}$ China University of Petroleum (East China), Qingdao 266580, China \\ ${ }^{2}$ CNOOC Research Institute Co., Ltd., Beijing 100028, China \\ ${ }^{3}$ Research Institute of Exploration and Development, Tarim Oilfield Company, PetroChina, Korla, Xinjiang 84100, China \\ ${ }^{4}$ China University of Petroleum (Beijing), Beijing 201149, China
}

Correspondence should be addressed to Jing Li; lijing0681@163.com and Yongcun Feng; yfeng@cup.edu.cn

Received 28 June 2021; Accepted 16 August 2021; Published 24 September 2021

Academic Editor: Andrew H. Manning

Copyright (c) 2021 Jiageng Liu et al. This is an open access article distributed under the Creative Commons Attribution License, which permits unrestricted use, distribution, and reproduction in any medium, provided the original work is properly cited.

Fracability evaluation is the basis of reservoir fracturing and fracturing zone optimization. The tight sandstone reservoir is characterized by low porosity and low permeability, which requires hydraulic fracturing to improve industrial productivity. In this study, a systematic model was proposed for the fracability evaluation of tight sandstone reservoirs. The rock mechanics tests and sonic tests demonstrated that tight sandstone reservoir is characterized by high brittleness, high fracture toughness, and weak development of natural fractures. Numerical simulation was used to analyze the change of reservoir parameters during hydraulic fracturing and the influence of in situ stress on fracture propagation. The results showed that when the horizontal stress anisotropy coefficient is small, natural fractures may lead hydraulic fractures to change direction, and complex fracture networks are easily formed in the reservoir. The horizontal stress anisotropy coefficient ranges from 0.23 to 0.52 , and it is easy to produce fracture networks in the reservoir. A new fracability evaluation model was established based on the analytic hierarchy process (AHP). The fracability of tight sandstone reservoir is characterized by the fracability index (FI) and is divided into three levels. Based on the model, this study carried out fracability evaluation and fracturing zone optimization in the study area, and the microseismic monitoring results verified the accuracy of the model.

\section{Introduction}

With the increasing demand for oil and gas resources, the development of unconventional energy has gained more and more attention [1-3]. The unconventional gas reservoir is commonly defined as a reservoir with low permeability (less than $0.1 \mathrm{mD}$ ) [4]. Because of its low permeability, hydraulic fracturing is needed [5, 6]. Chong et al. [7] defined the reservoir fracability for the first time; that is, reservoir can be effectively fractured to increase production in the process of hydraulic fracturing. Fracability evaluation is the basis of hydraulic fracturing and fracturing zone optimization.

In fracability evaluation, it is crucial to determine the parameters affecting hydraulic fracturing. Rickman et al. [8] found that rocks with higher brittleness have higher elastic modulus and lower Poisson's ratio. Some scholars [9, 10] used brittleness index to characterize the fracability of shale reservoir and found that the larger the brittleness index, the better the fracturing effect. However, further research showed that it is not comprehensive to characterize the reservoir fracability only by brittleness index, and there are other factors. Fracture toughness is another important parameter which reflects the energy consumed in the process of rock fracture. Sato and Hashida [11] considered the influence of fracture toughness in hydraulic fracturing and found that the higher the fracture toughness of reservoir, the more difficult it is to be fractured. Huang et al. [12] investigated the effects of rock inherent heterogeneity and grain size on hydraulic fracture initiation and propagation for different propagation regimes through two dimensional discrete element modelings. 
Scholars $[13,14]$ found that fracability is affected by many factors, including not only the characteristics of rock but also the geological characteristics of reservoir. Natural fracture is a weak part of mechanics, which influences the generation and extension of hydraulic fracture [15]. Barani et al. [16] proposed a numerical model which can appropriately simulate two possibilities of the interaction (opening and crossing) of a hydraulic fracture with a natural fracture. Sanchez et al. [17] predicted three main possibilities of fracture interaction (arrest, opening, and crossing) and found that the most important parameters affecting fracture interaction are in situ stresses and the angle of approach between hydraulic fracture and natural fracture. Reservoir rocks and fluids are jointly affected by in situ stress. In situ stress and its anisotropy affect the generation and propagation of hydraulic fractures [18]. Zhu et al. [19] conducted laboratory experiments of hydraulic fracturing and found that as the angle between the direction of wellbore axis and the maximum horizontal stress increases, the fracture roughness, fracture continuity, and the number of secondary fractures increase. Yan et al. [20] found that as the angle between the direction of wellbore axis and the maximum horizontal stress increases, the pressures of fracture initiation and propagation grow. Rabbel et al. [21] found that the fracture opening and propagation mode are related to the magnitude of external stress anisotropy, and strongly anisotropic far-field stresses lead to highly directional connectivity, which may translate to anisotropic fracture permeability. Liu et al. [22] developed a novel fracability evaluation model of hydratebearing sediments integrating hydrate saturation, brittleness, stress anisotropy, and mineral composition.

As discussed above, the reservoir fracability is related to many factors, including elastic parameters, brittleness, fracture toughness, natural fractures, and external stress anisotropy. It is difficult to establish a fracability evaluation model considering all factors. On the other hand, in situ stress characteristics have a great influence on hydraulic fracturing, but the fracability study considering external stress anisotropy is very rare. Therefore, this study analyzed the influencing factors of fracability of tight sandstone reservoir based on logging data and laboratory tests and further studied the influence of in situ stress characteristics on hydraulic fracturing through numerical simulation. Finally, we proposed a new systematic model for the fracability evaluation of tight sandstone reservoirs.

\section{Fracability Parameters}

The parameters that affect the fracability were analyzed based on logging data and laboratory tests in this section, which provides the basis for subsequent hydraulic fracturing modeling and fracability evaluation.

2.1. Geological Settings. Block 4 of Junggar Basin is located in the Xinjiang Uygur Autonomous Region of China. The strata in this area are well developed and generally gentle, showing the characteristics of thick in the south and thin in the north, thick in the west, and thin in the east. The study area is located in the center of oil source and favorable direc- tion of oil and gas migration, with high oil and gas abundance. The structure of the study area is shown in Figure 1.

The genesis of tight sandstone reservoir is complex, with low porosity, low permeability, complex pore structure, and secondary pore development. The exploration report shows that the average porosity of tight sandstone in the study area is $4.1 \%$, and the permeability is $0.132 \sim 0.839 \mathrm{mD}$. Although the study area is rich in oil and gas reserves, trial production is not ideal. Conventional exploitation means cannot meet production requirements; so, hydraulic fracturing is needed.

\subsection{Rock Mechanic Parameters}

2.2.1. Elastic Modulus and Poisson's Ratio. This work used the sonic logging-based method to calculate the rock mechanic parameters of continuous formation, and the dynamic elastic parameters can be calculated using the transit time of P-and S-waves [23, 24]. Therefore, we carried out triaxial compression tests and sonic tests on 15 rock samples $(\Phi 25 \times 50 \mathrm{~mm})$ in the study area. In order to obtain accurate dynamic and static parameter conversion formula, the confining pressure change range is $0-70 \mathrm{MPa}$. The purpose of the experiment is to measure the acoustic wave velocity corresponding to the elastic parameters of rock under different confining pressure. The comparison of some cores before and after the experiment is shown in Figure 2. It can be seen that the rocks have undergone shear failure. The elastic modulus, Poisson's ratio, and wave velocity under different confining pressures were measured. The results are shown in Table 1, and the stress-strain curves are shown in Figure 3.

It can be seen that with the increase in confining pressure, elastic modulus increases, Poisson's ratio decreases, and wave velocity increases. The dynamic elastic modulus and dynamic Poisson's ratio are calculated using the transit time of P- and S-waves, as shown in Eqs. (1) and (2):

$$
\begin{aligned}
& E_{d}=\frac{\rho\left(3 \Delta t_{s}^{2}-4 \Delta t_{p}^{2}\right)}{\Delta t_{s}^{2}\left(\Delta t_{s}^{2}-\Delta t_{p}^{2}\right)} \times 9.299 \times 10^{4} \\
& \mu_{d}=\frac{0.5 \Delta t_{s}^{2}-\Delta t_{p}^{2}}{\Delta t_{s}^{2}-\Delta t_{p}^{2}}
\end{aligned}
$$

where $E_{d}$ is the dynamic elastic modulus, GPa, $\mu_{d}$ is the dynamic Poisson ratio, $\Delta t_{p}$ and $\Delta t_{s}$ are the $\mathrm{P}$-wave transit time and $\mathrm{S}$-wave transit time, $\mu \mathrm{s} / \mathrm{ft}$, and $\rho$ is the rock density, $\mathrm{g} / \mathrm{cm}^{3}$.

Fit the dynamic and static mechanical parameters and determine the fitting equation:

$$
\left\{\begin{array}{l}
E_{s}=0.680 E_{d}-5.321 \\
\mu_{s}=0.611 \mu_{d}+0.046
\end{array}\right.
$$

where $E_{s}$ is the static elastic modulus, GPa, and $\mu_{s}$ is the static Poisson ratio.

Based on sonic logging data ( $\mathrm{P}$ - and $\mathrm{S}$-wave transit time in Figure 4), Eqs. (1)-(3) can be used to calculate the elastic 


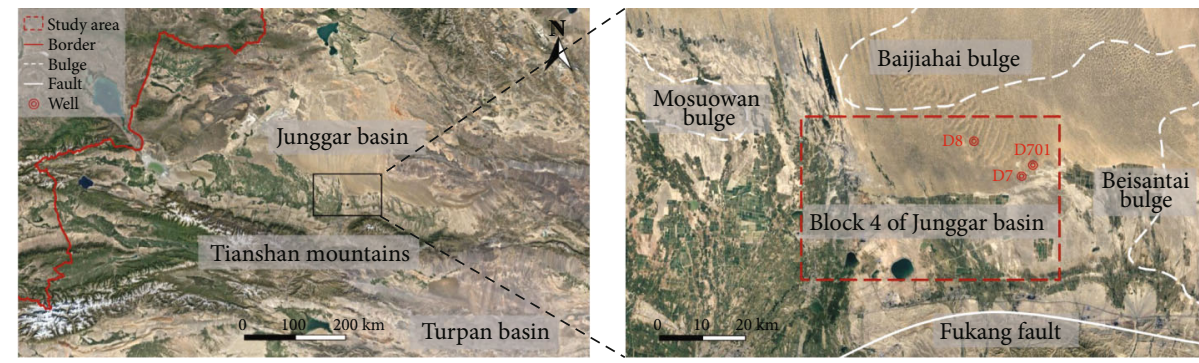

FIGURE 1: Structure of the study area.

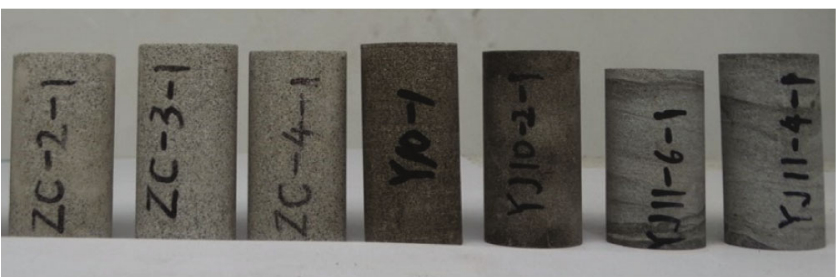

(a)

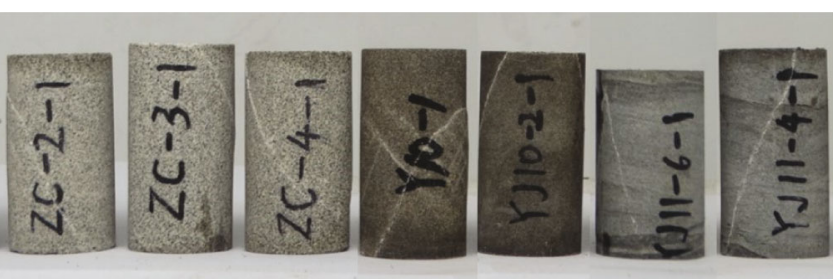

(b)

Figure 2: Tight sandstone cores. (a) Initial state. (b) After failure.

TABLE 1: Results of triaxial compression tests and sonic tests.

\begin{tabular}{|c|c|c|c|c|c|c|}
\hline $\begin{array}{l}\text { Core } \\
\text { number }\end{array}$ & $\begin{array}{l}\text { Confining pressure/ } \\
\mathrm{MPa}\end{array}$ & $\begin{array}{l}\text { Peak strength/ } \\
\mathrm{MPa}\end{array}$ & $\begin{array}{l}\text { Static Poisson's } \\
\text { ratio }\end{array}$ & $\begin{array}{l}\text { Static elastic modulus/ } \\
\text { GPa }\end{array}$ & $\begin{array}{c}\text { P-wave velocity/ } \\
\mathrm{m} \cdot \mathrm{s}^{-1}\end{array}$ & $\begin{array}{c}\text { S-wave velocity/ } \\
\mathrm{m} \cdot \mathrm{s}^{-1}\end{array}$ \\
\hline 1 & 0 & 54.6 & 0.258 & 8.26 & 3632 & 1994 \\
\hline 2 & 10 & 106.9 & 0.256 & 11.74 & 3735 & 2052 \\
\hline 3 & 10 & 140.8 & 0.219 & 16.28 & 4122 & 2400 \\
\hline 4 & 20 & 136.0 & 0.185 & 15.26 & 3965 & 2442 \\
\hline 5 & 20 & 142.9 & 0.174 & 14.48 & 3919 & 2427 \\
\hline 6 & 30 & 164.9 & 0.168 & 18.90 & 4180 & 2630 \\
\hline 7 & 30 & 172.4 & 0.188 & 17.84 & 4025 & 2447 \\
\hline 8 & 40 & 173.4 & 0.203 & 16.72 & 4155 & 2470 \\
\hline 9 & 40 & 179.8 & 0.205 & 17.33 & 4054 & 2428 \\
\hline 10 & 50 & 194.6 & 0.217 & 18.80 & 4283 & 2521 \\
\hline 11 & 50 & 186.3 & 0.216 & 17.84 & 4232 & 2503 \\
\hline 12 & 60 & 206.4 & 0.188 & 19.84 & 4225 & 2547 \\
\hline 13 & 60 & 210.5 & 0.198 & 19.53 & 4203 & 2524 \\
\hline 14 & 70 & 237.3 & 0.197 & 22.16 & 4293 & 2604 \\
\hline 15 & 70 & 242.4 & 0.202 & 23.53 & 4322 & 2634 \\
\hline
\end{tabular}

modulus and Poisson's ratio of continuous formation, as shown in Figure 4.

2.2.2. Brittleness. Rock brittleness is an important parameter that affects the reservoir fracability. Obert and Duvall [25] described brittleness as a property of materials that fracture with a little or no plastic flow. In rock mechanics, brittleness is defined as the absence of a plastic deformation before final failure [26]. Brittleness index can be defined by the stressstrain data obtained from uniaxial or triaxial compression tests, that is, the ratio of elastic strain energy to total strain energy at rock failure $[9,27]$. According to the results of the triaxial compression tests, Eq. (4) is used to calculate the brittleness index of 15 cores.

$$
B_{I}=\frac{\int_{0}^{\varepsilon_{0}} \sigma_{s} \varepsilon_{s} d \varepsilon}{\int_{0}^{\varepsilon_{0}} \sigma_{l} \varepsilon_{l} d \varepsilon},
$$

where $B_{I}$ is the brittleness index, $\varepsilon_{0}$ is the strain at rock failure, $\sigma_{s}$ and $\varepsilon_{s}$ are the stress and linear elastic strain of linear segment of stress-strain curve, respectively, and 


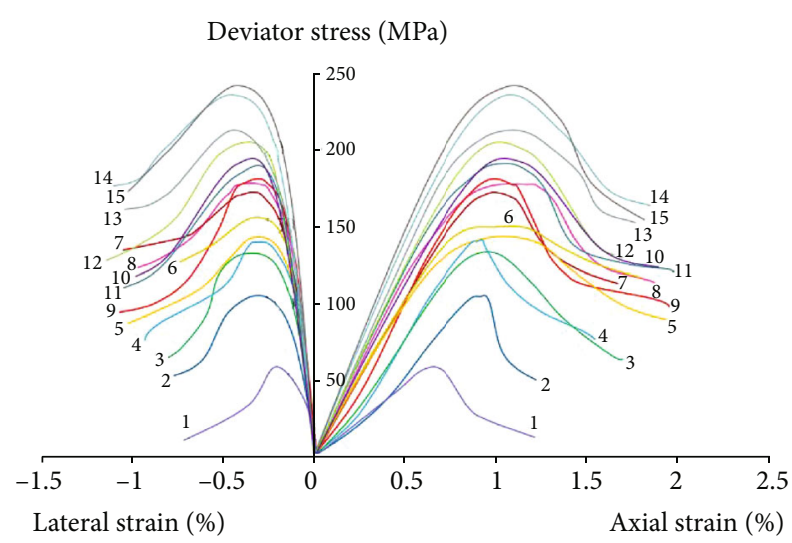

FIGURE 3: Stress-strain curves of 15 cores.

$\sigma_{l}$ and $\varepsilon_{l}$ are the stress and strain before rock completely failure, respectively.

The sonic logging-based method is also used to calculate the brittleness index of continuous formation. The specific process will not be repeated. The results are shown in Figure 4 . The brittleness index ranges from 0.50 to 0.83 ; so, the rock brittleness is high.

2.2.3. Fracture Toughness. The failure behavior of reservoir rock is essentially a macroscopic manifestation of energy dissipation and release. Fracture energy, especially postpeak fracture energy, reflects the energy consumed by fracture propagation and is an important factor in determining whether a rock fracture occurs. In this study, a triaxial compression test-based method Wang [28] was used to calculate the postpeak fracture energy and postpeak fracture energy density of 15 cores. The elastic modulus is an important factor affecting the fracture energy. So, we established the fitting formula of elastic modulus and postpeak fracture energy density and found that the fitting result (Figure 5) was good. Therefore, this study used postpeak fracture energy density to characterize the fracture toughness. The fitting equation is shown in Eq. (5).

$$
W_{\text {post }}=0.249 E^{2}+3.155 E \text {, }
$$

where $W_{\text {post }}$ is the postpeak fracture energy density, $N \cdot \mathrm{mm} \cdot \mathrm{mm}^{-3}$, and $E$ is the elastic modulus, GPa.

Based on the calculation result of elastic modulus in Section 2.2.1, Eqs. (5) can be used to calculate the fracture toughness of continuous formation, as shown in Figure 4. The fracture energy density is mostly between 83.5 and $275.4 \mathrm{~N} \cdot \mathrm{mm} \cdot \mathrm{mm}^{-3}$; so, the energy required for fracture propagation is large.

\subsection{In Situ Stress Characteristics}

2.3.1. In Situ Stress. The in situ stress was calculated based on logging data and the analysis results above, as shown in Eq. (6).

$$
\left\{\begin{array}{l}
\sigma_{v}=\bar{\rho} h_{0} g+\int_{h_{0}}^{h} \rho g d h, \\
\sigma_{h}=\frac{\mu}{1-\mu}\left(\sigma_{v}-\alpha P_{p}\right)+\beta_{h}\left(\sigma_{v}-\alpha P_{p}\right)+\alpha P_{p}, \\
\sigma_{H}=\frac{\mu}{1-\mu}\left(\sigma_{v}-\alpha P_{p}\right)+\beta_{H}\left(\sigma_{v}-\alpha P_{p}\right)+\alpha P_{p},
\end{array}\right.
$$

where $\sigma_{v}$ is the vertical stress, $\mathrm{MPa}, \bar{\rho}$ is the average density of overlying strata, $\mathrm{g} / \mathrm{cm}^{3}, h_{0}$ is the initial depth of target layer, $\mathrm{m}, \rho$ is the density of rock layer, $\mathrm{g} / \mathrm{cm}^{3}, g$ is the gravity acceleration, $\mathrm{m} / \mathrm{s}^{2}, \sigma_{H}$ and $\sigma_{h}$ are the maximum and minimum horizontal principal stress, $\mathrm{MPa}$, and $\beta_{H}$ and $\beta_{h}$ are the tectonic stress coefficients in the direction of the maximum and minimum horizontal principal stress. According to the result of field stress test, $\beta_{H}$ and $\beta_{h}$ are determined as 1.069 and 0.787 , respectively; $\alpha$ is the significant stress coefficient; $P_{p}$ is the pore pressure of formation, MPa.

The in situ stress in different depths is shown in Figure 4.

2.3.2. Horizontal Stress Anisotropy. The horizontal principal stress anisotropy was characterized by the horizontal stress anisotropy coefficient.

$$
K_{h}=\frac{\sigma_{H}-\sigma_{h}}{\sigma_{h}} .
$$

The horizontal stress anisotropy coefficient in different depths is shown in Figure 4.

2.4. Development Degree of Natural Fracture. This study used rock rupture criterion to determine the shear fracture rate and tensile fracture rate of different depth strata and calculated the weighted sum of the two to obtain fracture development index, which can quantitatively characterizes the development degree of natural fractures in the study area.

The equation of shear fracture rate is shown in Eq. (8). The larger the shear fracture rate is, the stronger the shear failure degree of reservoir rock is.

$$
I_{n}=\frac{\tau}{|\tau|}=\frac{\left(\sigma_{H}-\sigma_{h}\right)}{2|\tau|} \sin 2 \alpha,
$$

where $\tau$ is the shear stress on the rock failure surface, $\mathrm{MPa}$, $|\tau|$ is the shear strength of rock, $\mathrm{MPa}$, and $\alpha$ is the rock fracture angle, ${ }^{\circ}$.

The equation of tensile fracture rate is shown in Eq. (9). The larger the tensile fracture rate is, the stronger the tensile failure degree of reservoir rock is.

$$
I_{t}=\frac{\sigma_{t}}{\left|\sigma_{t}\right|}=\frac{\left(\sigma_{H}-\sigma_{h}\right)^{2}}{8\left(\sigma_{H}+\sigma_{h}\right)\left|\sigma_{t}\right|},
$$

where $\sigma_{t}$ is the tensile stress on the rock failure surface, $\mathrm{MPa}$, and $\left|\sigma_{t}\right|$ is the tensile strength of rock, MPa. 


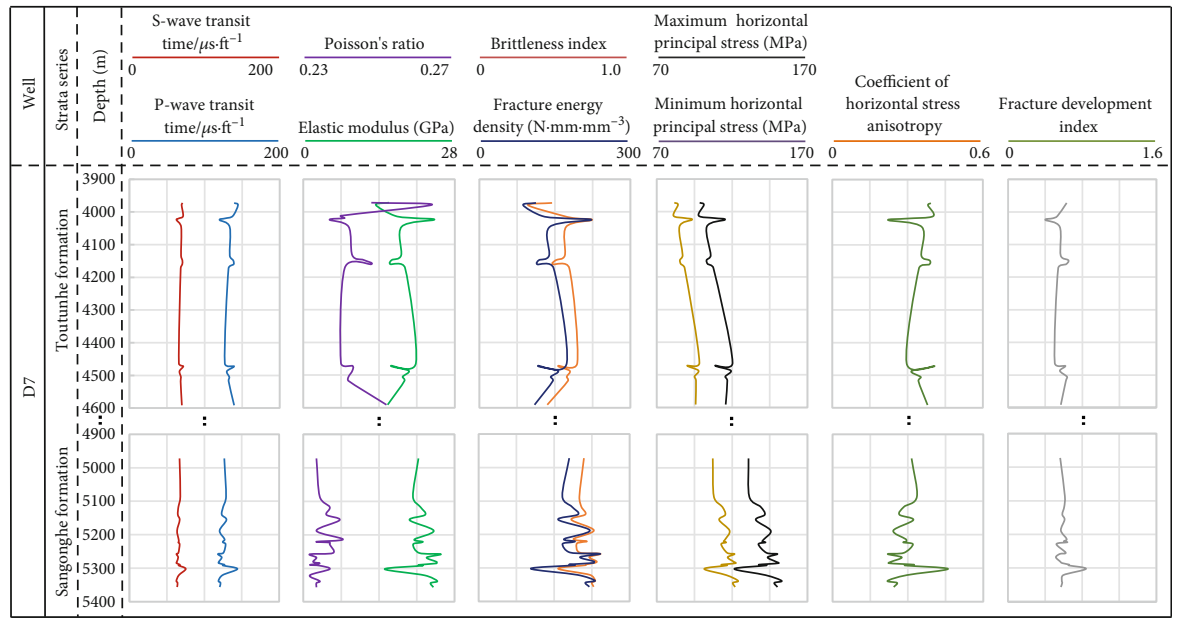

(a)

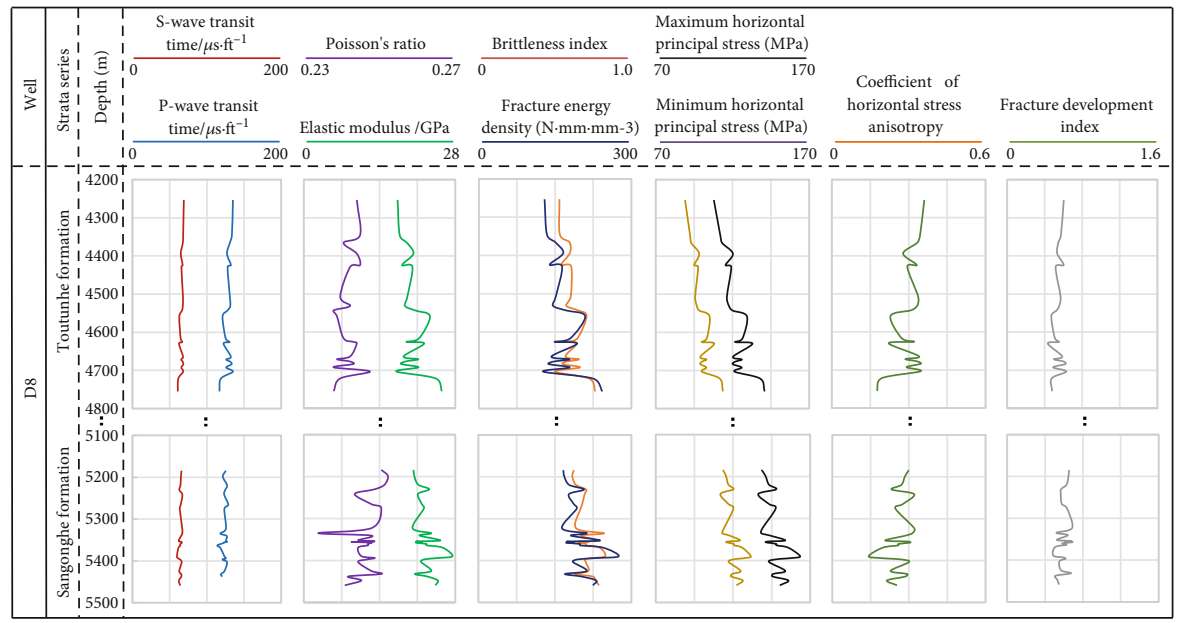

(b)

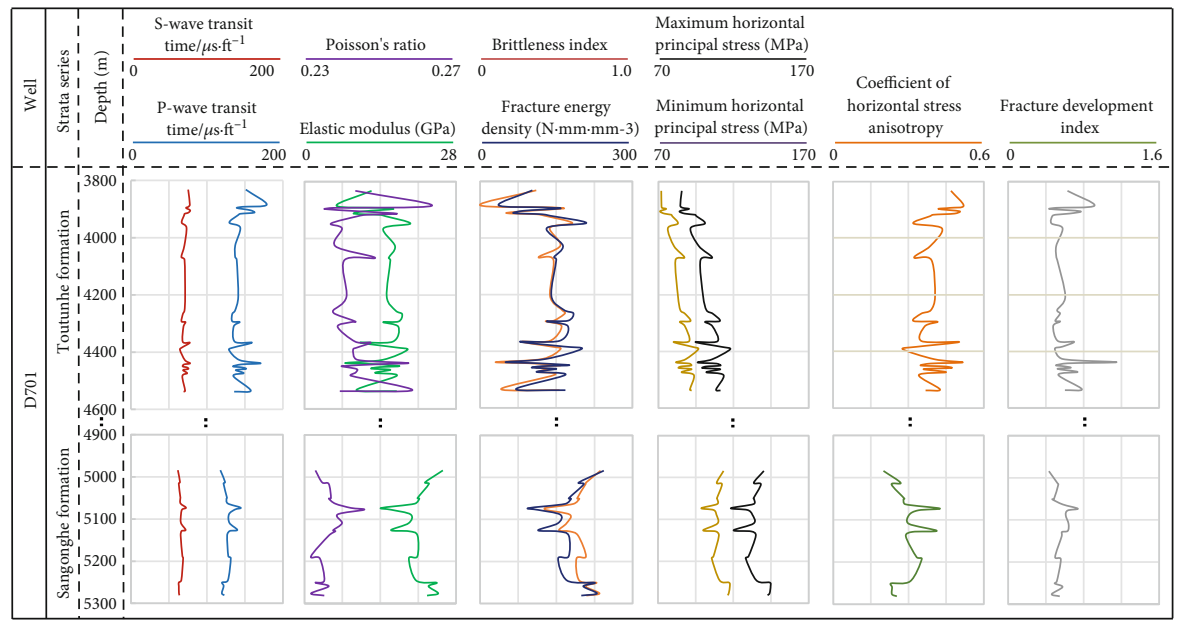

(c)

FIGURE 4: Fracability related parameters of three wells in the study area: (a) Well D7, (b) well D8, and (c) well D701.

The equation of fracture development index is shown in Eq. (10).

$$
I=a I_{n}+b I_{t},
$$

where $a$ and $b$ are the proportions of shear fracture and tensile fracture, respectively. According to the statistical results of field data, $a$ and $b$ in the study area are 0.7 and 0.3 , respectively. 


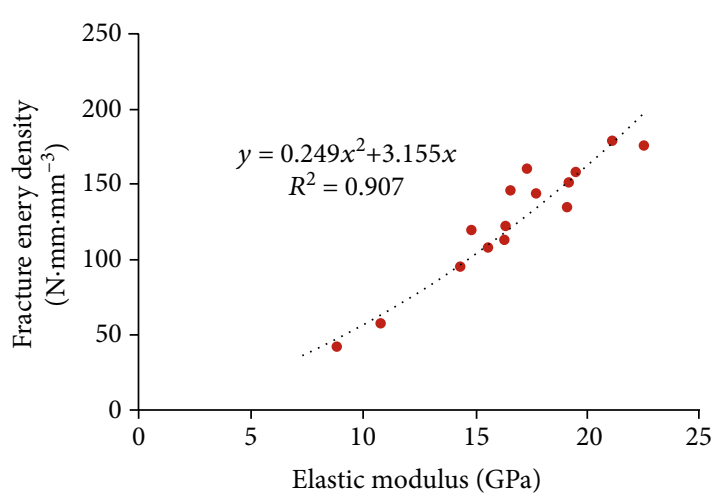

Figure 5: Fitting curve of elastic modulus and fracture energy density.

The fracture development index in different depths is shown in Figure 4. The results showed that the fracture development index ranges from 0.4 to 0.8 , and most of the study area strata are slightly fracture-developed zones. The fracture development index of a few strata is greater than 0.8 , which are fracture-developed zones.

2.5. Selection and Analysis of Fracability Parameters. The purpose of hydraulic fracturing is to produce a complex fracture system. The process of producing a fracture system includes the generation and propagation of fractures. These two parts determine the effect of hydraulic fracturing. Rocks with high brittleness are more prone to fracture. In this study, the brittleness index is characterized by the ratio of elastic strain energy to total strain energy at rock failure (Eq. (3)). Fracture toughness affects fracture propagation. In general, the higher the fracture toughness, the more difficult the propagation of fractures. The postpeak fracture energy density is used to characterize the fracture toughness of rock. The brittleness index in the study area ranges from 0.50 to 0.83 , and the rock is relatively brittle. The fracture energy density mostly ranges from 83.5 to 275.4 $\mathrm{n} \cdot \mathrm{mm} \cdot \mathrm{mm}^{-3}$, which requires a large amount of energy for fracture propagation.

Natural fracture is a weak part of mechanics. On the one hand, natural fractures can cause stress changes near the wellbore. On the other hand, natural fractures can interact with induced fractures to affect the fracture propagation. The fracture development index mainly ranges from 0.4 to 0.8 , and most of the strata are slightly fracture-developed zones.

The in situ stress anisotropy affects the opening and propagation mode of fractures, but the current researches are few and not thorough.

As discussed above, this study considered four factors when establishing the fracability evaluation model, including rock brittleness, fracture toughness, natural fractures, and horizontal stress anisotropy coefficient. Because the influence of horizontal stress anisotropy is uncertain, this study carried out a numerical simulation in Section 3.

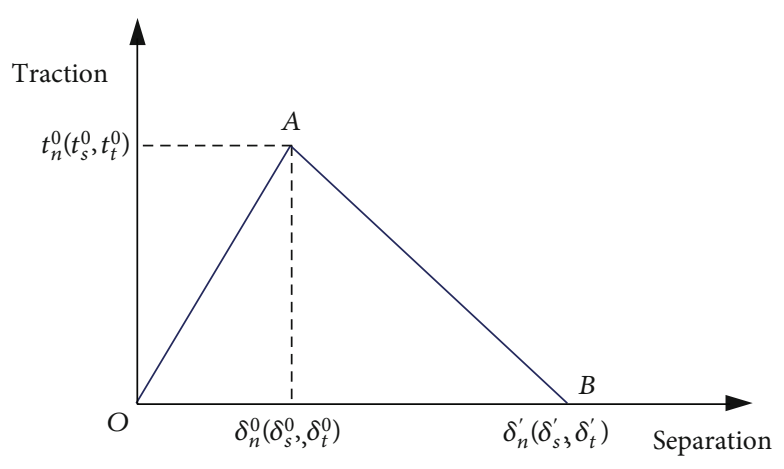

FIgURE 6: Bilinear constitutive model.

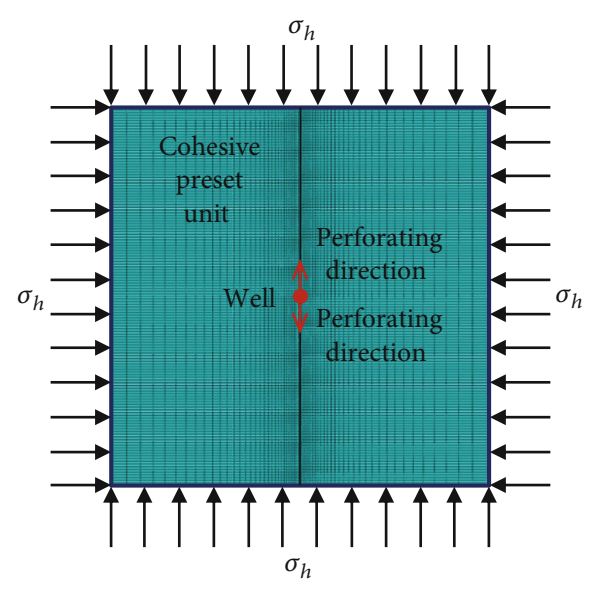

FIGURE 7: Finite element model and grid partition.

\section{Numerical Simulation of Hydraulic Fracturing}

Aiming at the problems analyzed in Section 2, this section carried out numerical simulation to analyze the changes of reservoir parameters during hydraulic fracturing and the influence of in situ stress on fracture propagation.

3.1. Numerical Model of Hydraulic Fracturing. Numerical simulation is carried out using the cohesive unit of ABAQUS software. The mechanical behavior of reservoir is described by the traction-separation criterion and bilinear constitutive relationships, and the model is shown in Figure 6.

In Figure 6, the bilinear constitutive model consists of a prepeak linear elastic stage and a postpeak stiffness decrease stage. The damage factor of the model is calculated by Eq. (11).

$$
D=\frac{\delta_{n}^{\prime}\left(\delta_{n}^{\max }-\delta_{n}^{0}\right)}{\delta_{n}^{\max }\left(\delta_{n}^{\prime}-\delta_{n}^{0}\right)},
$$

where $\delta_{n}^{\max }$ is the maximum displacement of the unit, $\mathrm{m} ; \delta_{n}^{\prime}$ is the displacement at unit failure, $\mathrm{m} ; \delta_{n}^{0}$ is the displacement at the start of unit damage, $\mathrm{m}$. 
TABle 2: Parameters of numerical simulation.

\begin{tabular}{lccc}
\hline Parameters & Value & Parameters & Value \\
\hline Porosity & $10 \%$ & Permeability & $0.1 \mathrm{mD}$ \\
Elastic modulus & $20 \mathrm{GPa}$ & Poisson's ratio & 0.25 \\
Tensile strength & $8 \mathrm{MPa}$ & Shear strength & $20 \mathrm{MPa}$ \\
Vertical stress & $60 \mathrm{MPa}$ & Pore pressure & $40 \mathrm{MPa}$ \\
Maximum horizontal principal stress & $70 \mathrm{MPa}$ & Minimum horizontal principal stress & $50 \mathrm{MPa}$ \\
Fluid viscosity & $0.001 \mathrm{pa} \cdot \mathrm{s}$ & Filtration coefficient & $1.0 \times 10^{-14} \mathrm{~m} / \mathrm{pa}$ \\
\hline
\end{tabular}

In the postpeak stiffness decrease stage, the damage evolution process of material is shown in Eq. (12).

$$
\begin{aligned}
t_{n} & = \begin{cases}(1-D) \bar{t}_{n}, & \bar{t}_{n} \geq 0, \\
\bar{t}_{n}, & \bar{t}_{n}<0,\end{cases} \\
t_{s} & =(1-D) \bar{t}_{s}, \\
t_{t} & =(1-D) \bar{t}_{t},
\end{aligned}
$$

where $\bar{t}_{n}$ is the normal stress, and $\bar{t}_{s}$ and $\bar{t}_{t}$ are tangential stresses.

The finite element model $(50 \times 50 \mathrm{~m})$ is shown in Figure 7. The maximum and minimum horizontal principal stresses are set in the horizontal direction. The perforation position is in the center of the model. The $\mathrm{COH} 24 \mathrm{P}$ is selected for cohesive unit.

Combined with the logging data and the experimental analysis in Section 2, the numerical simulation parameters are determined, as shown in Table 2.

3.2. Whole Process of Hydraulic Fracturing. Inject water at the perforation position, the injection rate is $0.001 \mathrm{~m}^{2} / \mathrm{s}$. The fracturing lasts for 100 seconds, and then the pump is shut down for 2400 seconds.

The distribution of injection pressure at different times is obtained by numerical simulation, as shown in Figure 8. For the convenience of observation, the deformation scaling factor is set to 100; that is, the crack element is expanded by 100 times. The white arrow represents the flow direction of fluid.

In Figure 8, the fracture is continuously extending along the direction of the maximum horizontal principal stress during water injection. The pressure around the fracture increases rapidly, the two tip areas of fracture are low stress areas, the two sides of fracture are high stress areas, and the closer to propagation area, the higher the stress is. After the pump is stopped, injection pressure gradually decreases, and the low stress areas near fracture tip disappear. When the pump is shut down for 2400 seconds, the regional stress gradually decreases from the fracture edge to the outside. In the whole process, the fluid first flows from the perforation to the low stress areas near fracture tip, and after the pump is shut down, the seepage direction is from the fracture to the surrounding.

The change law of injection pressure and fracture width in the fracturing process is researched, as shown in Figure 9.
In Figure 9, the generation and propagation of fracture during fracturing can be divided into the following four stages:

In the first stage, injection pressure increases rapidly at the moment of injection. At 2.1 seconds, injection pressure reaches the maximum value of $107.4 \mathrm{MPa}$, the reservoir is damaged, and the fracture width increases rapidly.

In the second stage, from 2.1 to 8.5 seconds, injection pressure gradually decreases to $61.5 \mathrm{MPa}$. Since the injection pressure is greater than the pressure required for fracture propagation, the fracture width increases, but the increase rate gradually decreases.

In the third stage, from 8.5 to 100.0 seconds, injection pressure is equal to the pressure required for fracture propagation; so, the fracture develops stably.

In the fourth stage, after stopping injection at $100.0 \mathrm{sec}-$ onds, injection pressure decreases slowly, and the fracture width is stable. At this time, it is necessary to select appropriate proppant to support the fracture.

3.3. Influence of Horizontal Stress Anisotropy on the Fracturing Effect. The horizontal stress anisotropy is the most intuitive factor reflecting the characteristics of in situ stress. In this section, the influence of horizontal stress anisotropy on reservoir fracturing with and without considering natural fractures is simulated and analyzed.

3.3.1. No Natural Fractures. The model without considering natural fracture is the same as that in 3.1. The minimum horizontal principal stress is $50 \mathrm{MPa}$, and the maximum horizontal principal stress is $50 \mathrm{MPa}, 60 \mathrm{MPa}, 70 \mathrm{MPa}$, and $80 \mathrm{MPa}$, respectively, which means the coefficient of horizontal stress anisotropy is $0,0.2,0.4$, and 0.6 , respectively. The numerical simulation results at 100 seconds during injection are shown in Figure 10. (when $\sigma_{H}=70 \mathrm{MPa}, K_{h}=0.4$, the result is shown in Figure 8(d).)

As shown in Figure 10, with the increase of horizontal stress anisotropy coefficient, the distributions of injection pressure have little change, and the fractures all extend in a single direction. The fracture width of the perforation location is extracted, as shown in Figure 11. There is little difference in fracture width under different horizontal stress anisotropy coefficients.

Therefore, the influence of horizontal stress anisotropy on fracturing effect is minimal when natural fractures are not considered. 


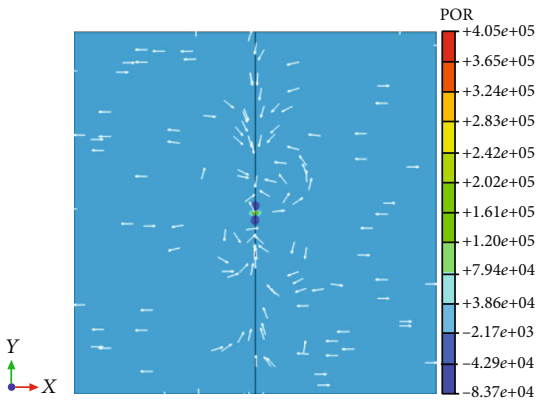

(a)

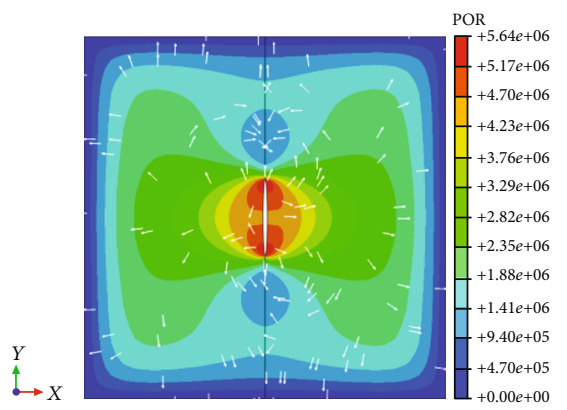

(c)

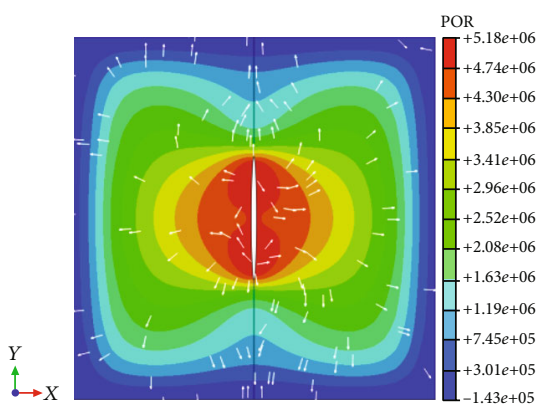

(e)

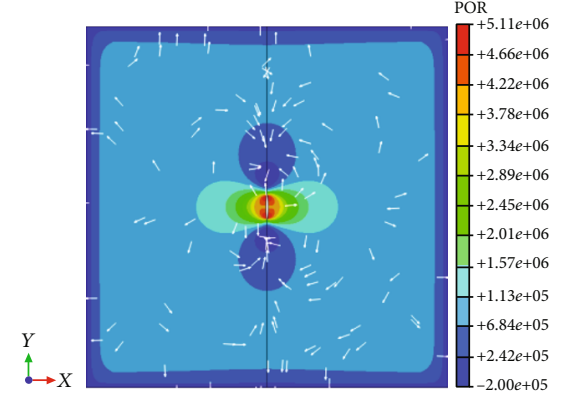

(b)

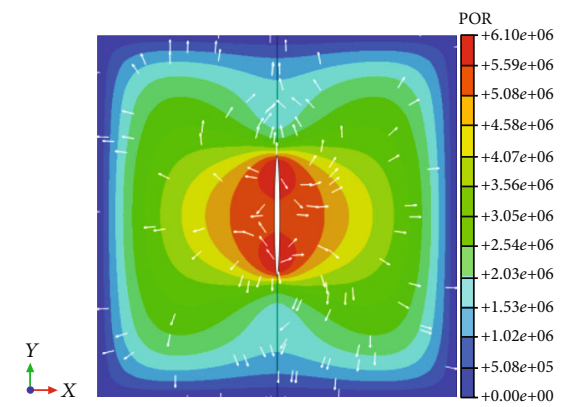

(d)

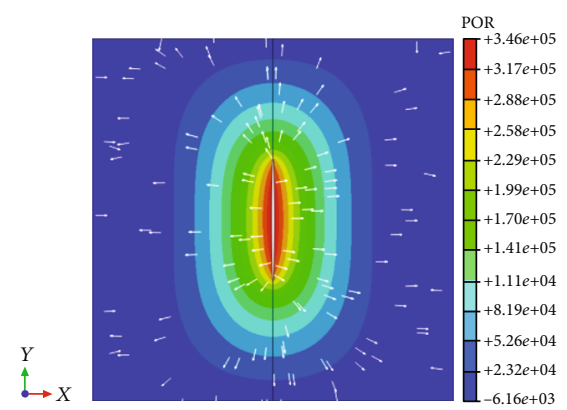

(f)

FIGURE 8: Injection pressure nephogram: (a) $0.10 \mathrm{~s}$ during injection, (b) $9.70 \mathrm{~s}$ during injection, (c) $50.46 \mathrm{~s}$ during injection, (d) $100 \mathrm{~s}$ during injection, (e) $5.13 \mathrm{~s}$ after injection stop, and (f) $2400 \mathrm{~s}$ after injection stop.

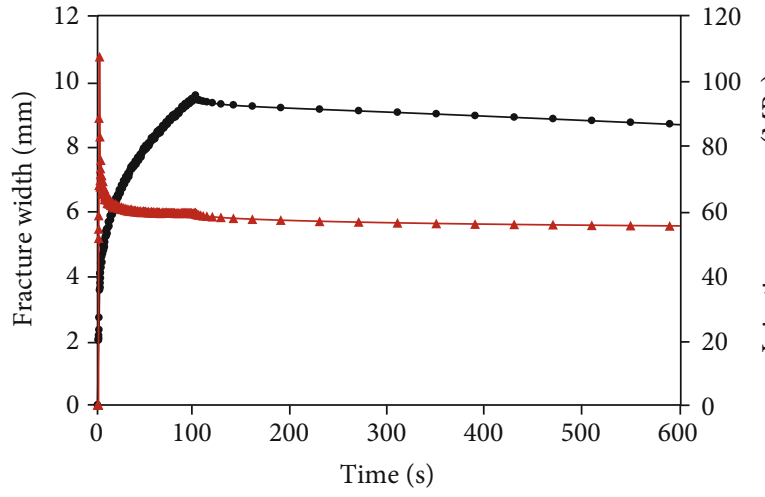

(a)

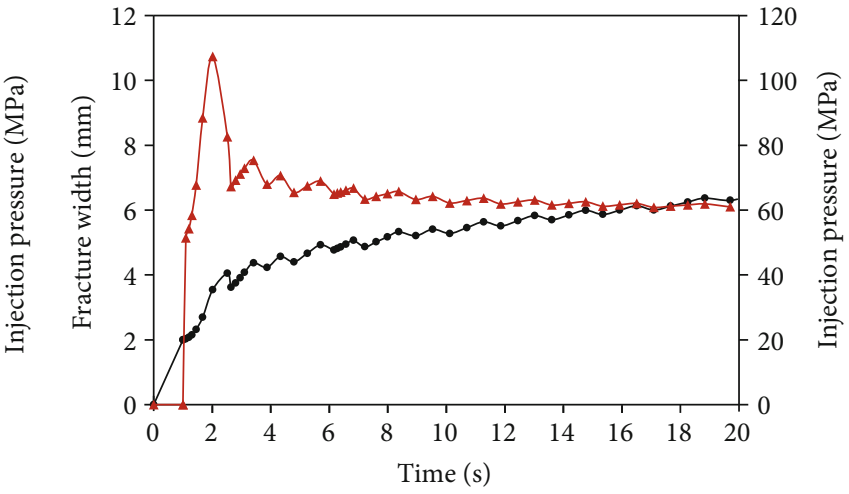

(b)

Figure 9: Variation curve of injection pressure and fracture width. (a) $0 \sim 600$ s. (b) $0 \sim 20$ s. 


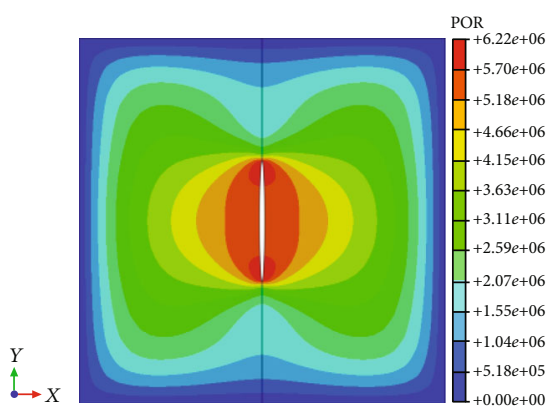

(a)

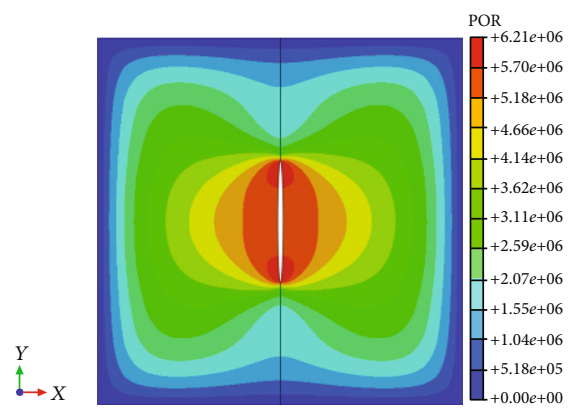

(b)

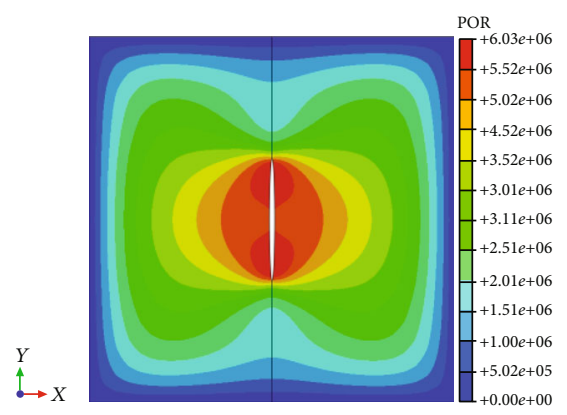

(c)

Figure 10: Injection pressure nephogram under different in situ stress conditions. (a) $\sigma_{H}=50 \mathrm{MPa}, K_{h}=0$. (b) $\sigma_{H}=60 \mathrm{MPa}, K_{h}=0.2$. (c) $\sigma_{H}=80 \mathrm{MPa}, K_{h}=0.6$

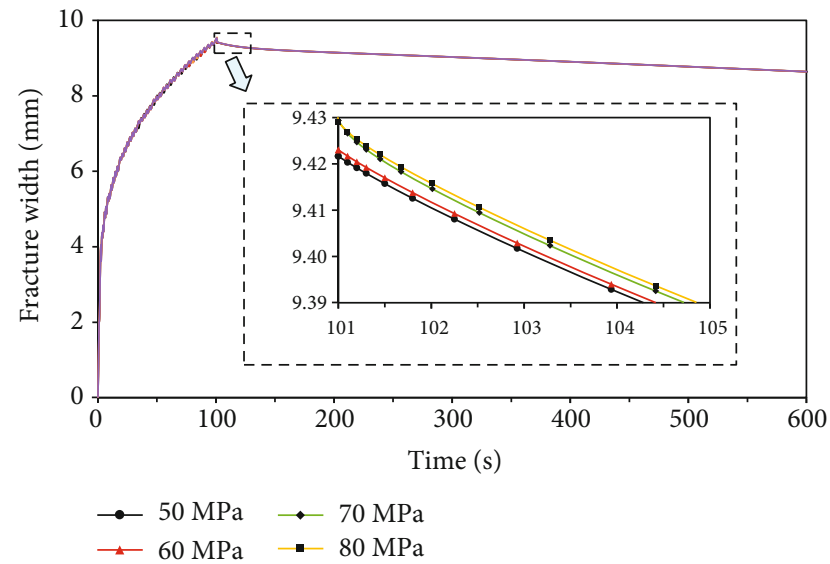

Figure 11: Variation curve of fracture width under different horizontal stress anisotropy coefficients.

3.3.2. Considering Natural Fractures. The model considering natural fracture is shown in Figure 12. The fracturing time is $150 \mathrm{~s}$, and the deformation scaling factor is 50 . Other parameters are the same as the model in 3.1.

(1) Condition 1: the maximum and minimum horizontal principal stresses are $70 \mathrm{MPa}$ and $50 \mathrm{MPa}$, respectively, which means the horizontal stress anisotropy coefficient is 0.4 . Figure 13 shows the process of fracture propagation. At the beginning of injection, the fracture propagates along the direction of maximum horizontal principal stress, and the distribution of injection pressure is similar to that without

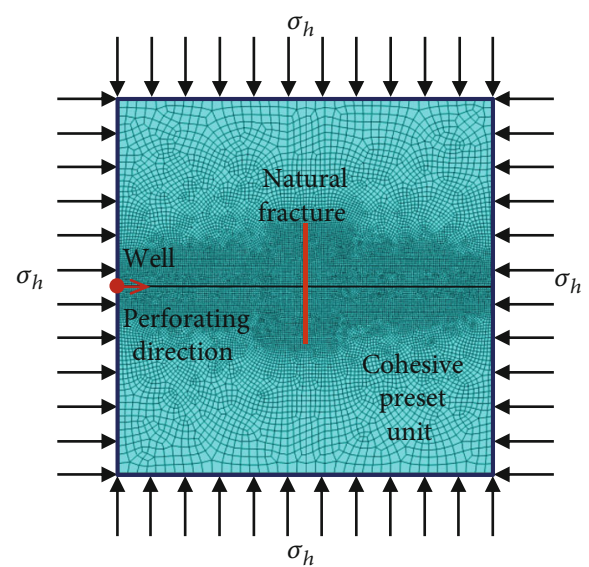

FIgURE 12: Finite element model considering natural fracture.

considering natural fractures. At 115.60 seconds, the hydraulic fracture intersects with the natural fracture, and the stress at the intersection increases gradually. Then, the hydraulic fracture passes through the natural fracture and continues to extend along the maximum horizontal principal stress direction. Injection pressure is low at the tip and high on both sides

(2) Condition 2: the maximum and minimum horizontal principal stresses are both $50 \mathrm{MPa}$, which means the horizontal stress anisotropy coefficient is 0 . Figure 14 shows the process of fracture propagation. At the beginning of injection, the fracture propagates 


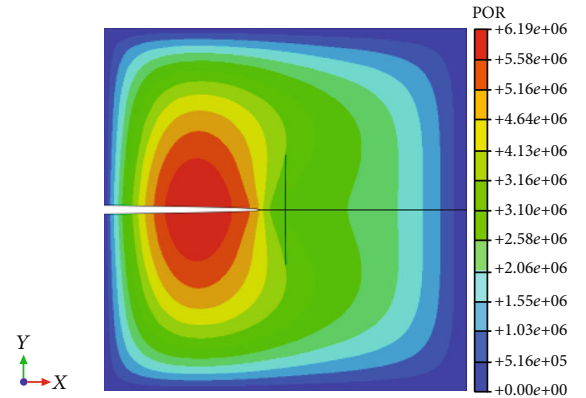

(a)

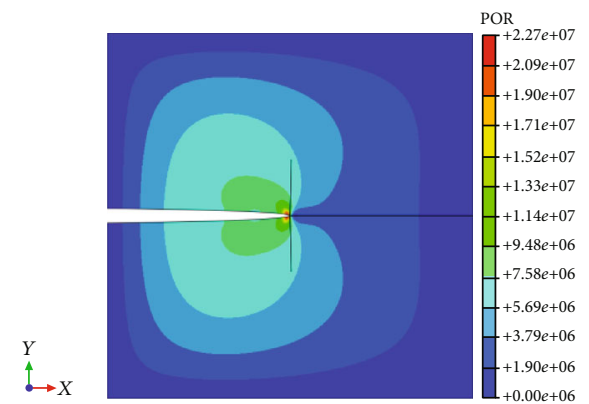

(b)

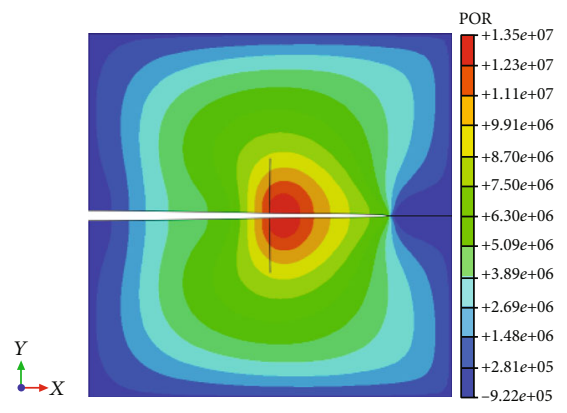

(c)

FIGURE 13: Injection pressure and fracture form under condition 1. (a) $60.12 \mathrm{~s}$ during injection. (b) $115.60 \mathrm{~s}$ during injection. (c) $150.00 \mathrm{~s}$ during injection.

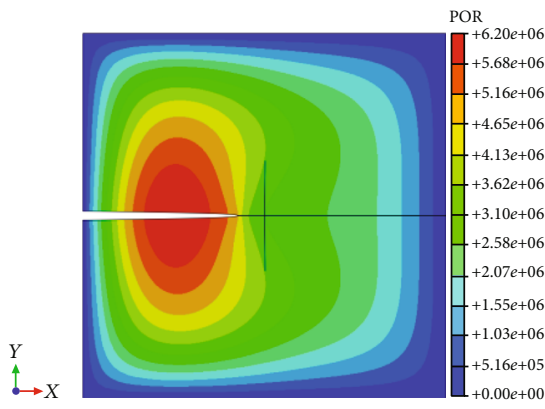

(a)

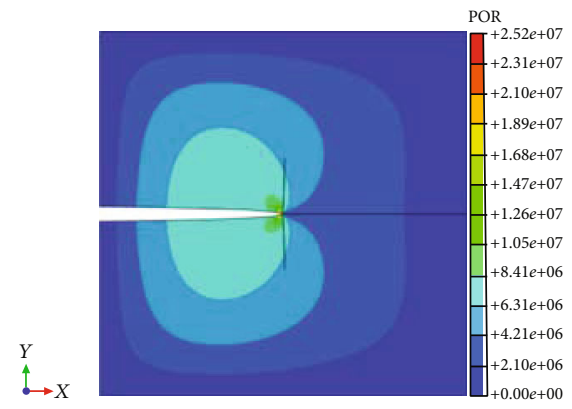

(b)

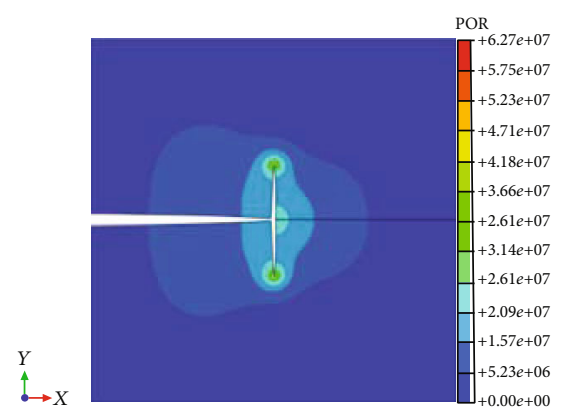

(c)

FIGURE 14: Injection pressure and fracture form under condition 2. (a) $60.12 \mathrm{~s}$ during injection. (b) $116.70 \mathrm{~s}$ during injection. (c) $150.00 \mathrm{~s}$ during injection.

along the direction of maximum horizontal principal stress. At 116.70 seconds, the hydraulic fracture intersects with the natural fracture, and the stress at the intersection increases gradually. Then, the nat- ural fracture opens, and the hydraulic fracture propagates forward along the natural fracture direction. The fracture tip is a high stress area, and the stress in other parts decreases 
In conclusion, when considering the influence of natural fractures, different in situ stress conditions have a greater impact on the propagation of hydraulic fracture. When the horizontal stress anisotropy coefficient is large, natural fracture has a little influence on the propagation of hydraulic fracture. Hydraulic fracture is easy to pass through natural fracture and continue to extend along the direction of the maximum horizontal principal stress. When the horizontal stress anisotropy coefficient is small, hydraulic fracture will not extend along the direction of the maximum horizontal principal stress after intersecting with natural fracture, but along the path of natural fracture. In other words, natural fracture is easy to induce the direction of hydraulic fracture to change, thus forming staggered fractures. In practice, there are many natural fractures in the reservoir. Therefore, the smaller the horizontal stress anisotropy coefficient is, the more complex fracture network forms in the reservoir during hydraulic fracturing.

\section{Evaluation of Fracability of Tight Sandstone Reservoir}

4.1. Evaluation Model. This work determines the weight of each influencing factor in fracability evaluation by analytic hierarchy process (AHP) [29] and establishes the fracability evaluation model of tight sandstone reservoir.

4.1.1. Establishment of the Hierarchical Structure Model. The problems to be solved are divided into disjoint levels. The factors in the criteria layer are independent of each other, serving the target layer and restricting the index layer, as shown in Figure 15.

4.1.2. Normalization of Parameters. Since each parameter has different dimensions, values, and ranges, the parameters are standardized first. The range transformation method is used to normalize the brittleness index, fracture energy density, horizontal stress anisotropy coefficient, and fracture development index.

Brittleness index and fracture development index are positive indexes. The larger the value is, the more advantageous it is for reservoir fracturing. The calculation formula is shown in Eq. (13).

$$
S=\frac{X-X_{\min }}{X_{\max }-X_{\min }},
$$

where $S$ is the normalized parameter value, $X_{\max }$ and $X_{\min }$ are the maximum and minimum value of parameters, respectively, and $X$ is the parameter value of the target interval.

Horizontal stress anisotropy coefficient and fracture energy density are the negative indexes. The larger the value is, the more disadvantageous it is for reservoir fracturing. The calculation formula is shown in Eq. (14).

$$
S=\frac{X_{\max }-X}{X_{\max }-X_{\min }} .
$$

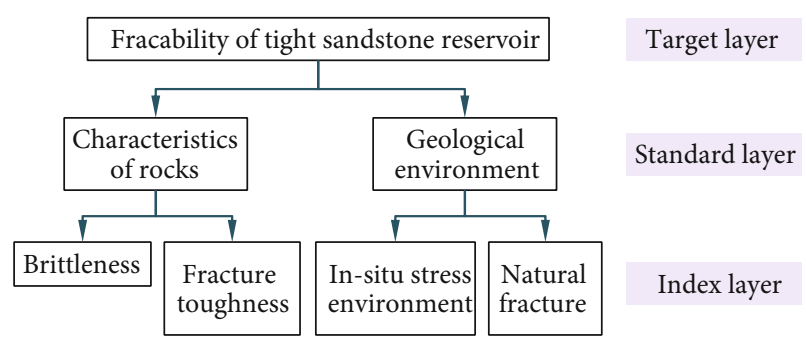

FIgURE 15: Hierarchical structure model.

4.1.3. Construction of Judgment Matrix. All the elements that affect the final goal are layered and constrained by the hierarchical model. Assuming that the elements of upper layer are the criteria, a comparison scale $a_{i j}$ can be used to express the relative importance of factor $i$ and factor $j$ in the next level, where $1<a_{i j}<9, a_{i j}=1 / a_{j i}$, and $a_{i i}=1$. The matrix composed of $a_{i j}$ is called judgment matrix $A$.

$$
A=\left[\begin{array}{cccc}
1 & a_{12} & \cdots & a_{1 n} \\
a_{21} & 1 & \cdots & a_{2 n} \\
\cdots & \cdots & 1 & \cdots \\
a_{n 1} & a_{n 2} & \cdots & 1
\end{array}\right] .
$$

Determine the relative importance of each two parameters by establishing a comparison matrix. The judgment matrix is established according to comparison matrix, and the weight of each parameter can be solved. However, this weight has the disadvantage of strong subjectivity. Therefore, the entropy method is used to modify the weights obtained by AHP [30]. The revised judgment matrix is shown in Table 3.

The weight of each parameter is determined according to judgment matrix, as shown in Eqs. (16)-(19).

$$
\begin{aligned}
\tilde{A}_{i j} & =\left(\frac{a_{i j}}{\sum_{i=1}^{n} a_{i j}}\right), \\
\tilde{W} & =\left(\sum_{j=1}^{n} \frac{a_{1 j}}{\sum_{i=1}^{n} a_{i j}}, \sum_{j=1}^{n} \frac{a_{2 j}}{\sum_{i=1}^{n} a_{i j}}, \cdots \cdots \sum_{j=1}^{n} \frac{a_{n j}}{\sum_{i=1}^{n} a_{i j}}\right)^{T}, \\
W & =\left(w_{1}, w_{2}, \cdots, w_{n}\right)^{T} .
\end{aligned}
$$

The maximum eigenvalue of matrix $A$ is

$$
\lambda_{\max }=\frac{1}{n} \sum_{i=1}^{n} \frac{(A W)_{i}}{w_{i}} .
$$

The weights of brittleness index, fracture energy density, horizontal stress anisotropy coefficient, and fracture development index are $0.42,0.23,0.23$, and 0.12 , respectively, and the maximum eigenvalue of judgment matrix is 4.012 . 
TABLE 3: Judgment matrix of fracability index.

\begin{tabular}{lcccc}
\hline$A$ & $\begin{array}{c}\text { Brittleness } \\
\text { index }\end{array}$ & $\begin{array}{c}\text { Fracture energy } \\
\text { density }\end{array}$ & $\begin{array}{c}\text { Horizontal stress anisotropy } \\
\text { coefficient }\end{array}$ & $\begin{array}{c}\text { Fracture development } \\
\text { index }\end{array}$ \\
\hline Brittleness index & 1 & 2 & 2 & 3 \\
Fracture energy density & $1 / 2$ & 1 & 1 & 2 \\
$\begin{array}{l}\text { Horizontal stress anisotropy } \\
\text { coefficient }\end{array}$ & $1 / 2$ & 1 & 1 & 2 \\
Fracture development index & $1 / 3$ & $1 / 2$ & $1 / 2$ & 1 \\
\hline
\end{tabular}

TABle 4: Fracability classification of tight sandstone reservoir.

\begin{tabular}{|c|c|c|c|c|c|c|}
\hline $\begin{array}{l}\text { Reservoir } \\
\text { type }\end{array}$ & $\begin{array}{l}\text { Brittleness } \\
\text { index }\end{array}$ & $\begin{array}{l}\text { Fracture energy } \\
\text { density }\end{array}$ & $\begin{array}{c}\text { Horizontal stress anisotropy } \\
\text { coefficient }\end{array}$ & $\begin{array}{l}\text { Fracture development } \\
\text { index }\end{array}$ & $\begin{array}{l}\text { Fracability } \\
\text { index }\end{array}$ & $\begin{array}{c}\text { Fracability } \\
\text { degree }\end{array}$ \\
\hline I & $0.5 \sim 1$ & $0.7 \sim 1$ & $0.6 \sim 1$ & $0.5 \sim 1$ & $0.569 \sim 1$ & High \\
\hline II & $0.3 \sim 0.5$ & $0.5 \sim 0.7$ & $0.4 \sim 0.6$ & $0.3 \sim 0.5$ & $0.369 \sim 0.569$ & Moderate \\
\hline III & $0 \sim 0.3$ & $0 \sim 0.5$ & $0 \sim 0.4$ & $0 \sim 0.3$ & $0 \sim 0.369$ & Low \\
\hline
\end{tabular}

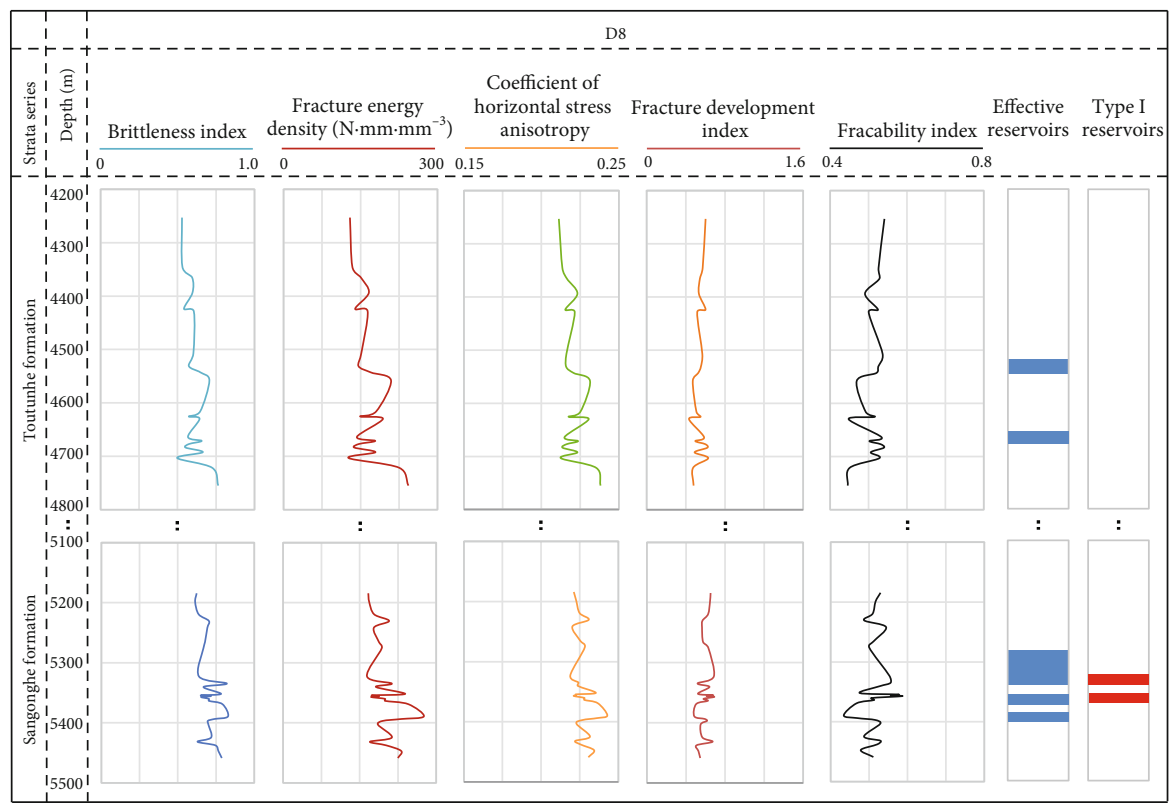

FIgURE 16: Fracability evaluation and fracturing zone optimization of well D8.

4.1.4. Consistency Check. To verify the rationality of $a_{i j}$, the consistency check of parameter weight is carried out.

$$
\mathrm{CI}=\frac{\lambda_{\max }-n}{n-1}, \mathrm{CR}=\frac{\mathrm{CI}}{\mathrm{RI}}
$$

where $\mathrm{CI}$ is the consistency index, $\mathrm{RI}$ is the average random consistency index, and when $n=4, \mathrm{RI}=0.89$; $\mathrm{CR}$ is the consistency proportion, and the smaller the value is, the better the consistency of the parameter weight is, which is generally bounded by 0.1 .

The results showed that $\mathrm{CI}=0.004$ and $\mathrm{CR}=0.0045 \leq$ 0.1 , which met the requirements.
4.1.5. Characterization and Classification of Fracability. Fracability index (FI) is used to characterize the fracability of tight sandstone reservoir:

$$
\mathrm{FI}=0.42 B_{\text {rit }}+0.23 W_{\text {post }}+0.23 K_{h}+0.12 I \text {, }
$$

where $B_{\text {rit }}$ is the brittleness index, $W_{\text {post }}$ is the fracture energy density, $K_{h}$ is the horizontal stress anisotropy coefficient, and $I$ is fracture development index. All of them are normalized values.

This work divides the fracability of tight sandstone reservoir into three grades, as shown in Table 4 . The reservoirs with fracability index greater than 0.569 are classified as type I reservoirs, which have high brittleness, poor fracture 
TABLE 5: The lower limit of the physical property of the Jurassic in the study area.

\begin{tabular}{lccc}
\hline Strata series & Method & Cutoff of porosity/\% & Cutoff of permeability/mD \\
\hline \multirow{3}{*}{ Toutunhe Formation } & Logging interpretation method & 4.22 & 0.14 \\
& Empirical statistics method & 4.30 & 0.14 \\
& Average & 4.26 & 0.14 \\
Sangonghe Formation & Logging interpretation method & 3.71 & 0.11 \\
& Empirical statistics method & 3.57 & 0.12 \\
\hline
\end{tabular}

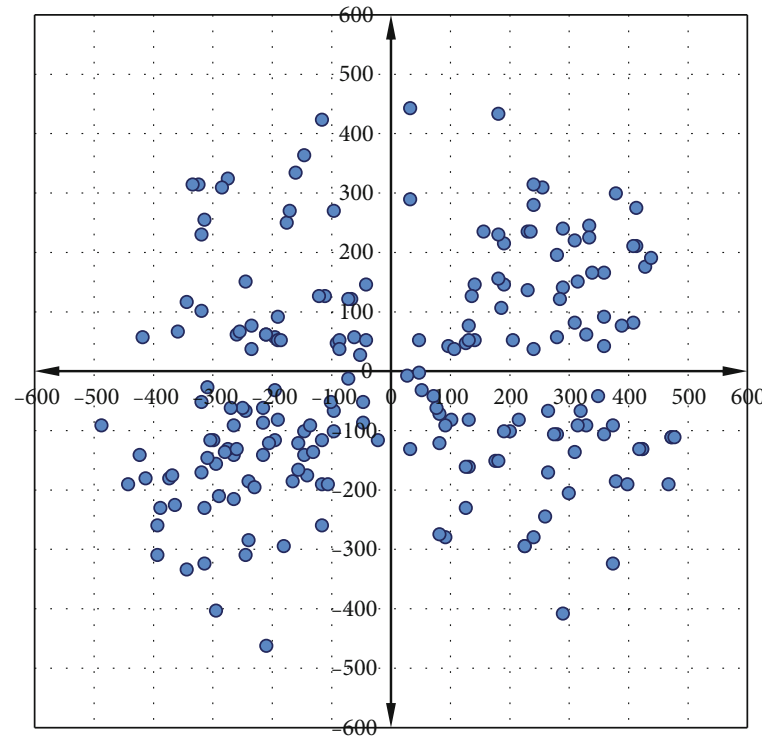

(a)

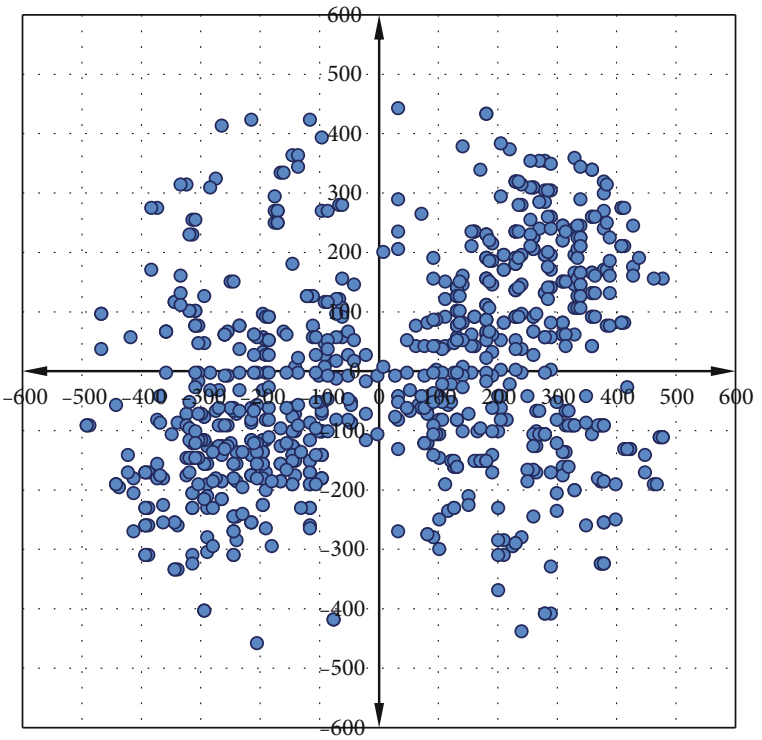

(b)

FIGURE 17: The microseismic point map of well D8. (a) Initial stage of hydraulic fracturing. (b) After hydraulic fracturing completed.

toughness, small horizontal stress anisotropy, and relatively developed fractures. The reservoirs with fracability index between 0.369 and 0.569 are classified as type II reservoirs, which should be reformed by increasing pressure or other methods. The reservoirs with fracability index less than 0.369 are classified as type III reservoirs, which are difficult to be fractured.

\subsection{Engineering Application and Model Validation. Well D8} was taken as an example, and the model established in this paper was used to evaluate the fracability. The result of microseismic monitoring verified the accuracy of the model.

4.2.1. Fracability Evaluation. The fracability index in different depths of well D8 is shown in Figure 16. According to the classification of fracability, reservoirs with fracability index greater than 0.569 are type I reservoirs, which are marked in red in Figure 16.

4.2.2. Selection of the Effective Reservoir. Effective reservoir refers to the reservoir that can store and percolate fluid (hydrocarbon or formation water) and produce oil and gas with industrial value. The petrophysical cutoff of the effective reservoir in the study area is determined by logging interpretation method and empirical statistics method, as shown in Table 5. Reservoirs with porosity and permeability greater than the petrophysical cutoff are effective reservoirs, which are marked in blue in Figure 16.

4.2.3. Optimization of Fracturing Zone. In Figures 16, 5120$5330 \mathrm{~m}$ and $5350-5365 \mathrm{~m}$ of well D8 have high fracability and are effective reservoirs, which can be regarded as the preferred fracturing zones.

4.2.4. Model Validation. In order to verify the correctness of the fracability evaluation model, we use microseismic monitoring to observe the fracturing effect. Microseismic monitoring is an effective method to study the characteristics of hydraulic fractures. Microseismicity is the occurrence of microearthquakes events caused by the injection of fluid into the borehole [31, 32]. Hydraulic fracturing was carried out in 5350-5365 m interval of well D8. The results of real-time microseismic monitoring before and after fracturing are compared, as shown in Figure 17.

In Figure 17, some northeast trending fractures occurred after hydraulic fracturing. Therefore, the purpose of fracturing is achieved, and the fracturing effect is good, which verifies the accuracy of the fracability evaluation model. 


\section{Conclusions}

A new systematic model for fracability evaluation of tight sandstone reservoir has been proposed in this study. It provides technical support for the exploration and development of tight oil and gas.

(i) Based on the triaxial compression tests and sonic tests, the parameters that affect fracability were analyzed. The brittleness index ranges from 0.50 to 0.83 , and the rock is relatively brittle. The fracture energy density mostly ranges from 83.5 to 275.4 $\mathrm{n} \cdot \mathrm{mm} \cdot \mathrm{mm}^{-3}$, which requires a large amount of energy for fracture propagation. The horizontal stress anisotropy coefficient ranges from 0.23 to 0.52 , which is easy to form fracture network. The fracture development index mainly ranges from 0.4 to 0.8 , and most of the strata are slightly fracture developed zones

(ii) Numerical simulation was used to analyze the changes of reservoir parameters during hydraulic fracturing and the influence of in situ stress on fracture propagation. When the horizontal stress anisotropy coefficient is large, the hydraulic fracture is easy to pass through the natural fracture and continues to extend along the direction of the maximum horizontal principal stress. When the horizontal stress anisotropy coefficient is small, the natural fracture is easy to induce the hydraulic fracture direction to change, and complex fracture networks are easily formed in the reservoir

(iii) A new fracability evaluation model of tight sandstone reservoir was established based on the analytic hierarchy process (AHP). The reservoir fracability is characterized by the fracability index (FI) and is divided into three levels. Based on the model, $5120-5330 \mathrm{~m}$ and $5350-5365 \mathrm{~m}$ of well D8 are selected as fracturing zones. The results of microseismic monitoring verify the accuracy of the model

\section{Data Availability}

Data are available upon request.

\section{Conflicts of Interest}

The authors declare that they have no conflicts of interest.

\section{Acknowledgments}

The research described in this paper was financially supported by the National Natural Science Foundation of China (41972138) and the National Great Science Fund of China (ZD2019-183-007 and 2016ZX05002-002).

\section{References}

[1] Q. Feng, S. Xu, X. Xing, W. Zhang, and S. Wang, "Advances and challenges in shale oil development: a critical review," Advances in Geo-Energy Research, vol. 4, no. 4, pp. 406-418, 2020.
[2] J. D. Hughes, "Energy: a reality check on the shale revolution," Nature, vol. 494, pp. 307-308, 2013.

[3] J. Li, L. Zhang, F. Yang, and L. Sun, "Positive measure and potential implication for heavy oil recovery of dip reservoir using SAGD based on numerical analysis," Energy, vol. 193, p. $116582,2020$.

[4] S. A. Holditch, "Tight gas sands," Journal of Petroleum Technology, vol. 58, no. 6, pp. 86-93, 2006.

[5] L. Britt, "Fracture stimulation fundamentals," Journal of Natural Gas Science and Engineering, vol. 8, pp. 34-51, 2012.

[6] L. Hu, A. Ghassemi, J. Pritchett, and S. Garg, "Characterization of laboratory-scale hydraulic fracturing for EGS," Geothermics, vol. 83, p. 101706, 2020.

[7] K. K. Chong, W. V. Grieser, A. Passman, H. C. Tamayo, N. Modeland, and B. E. Burke, "A completions guide book to shale-play development: a review of successful approaches toward shale-play stimulation in the last two decades," in Canadian Unconventional Resources and International Petroleum Conference, Calgary, Canada, 2010.

[8] R. Rickman, M. J. Mullen, J. E. Petre, W. V. Grieser, and D. Kundert, "A practical use of shale petrophysics for stimulation design optimization: all shale plays are not clones of the Barnett Shale," in SPE Annual Technical Conference and Exhibition, Denver, USA, 2008.

[9] R. Gholami, V. Rasouli, M. Sarmadivaleh, V. Minaeian, and N. Fakhari, "Brittleness of gas shale reservoirs: a case study from the North Perth basin, Australia," Journal of Natural Gas Science and Engineering, vol. 33, pp. 12441259, 2016.

[10] I. Rahimzadeh Kivi, M. Zare-Reisabadi, M. Saemi, and Z. Zamani, "An intelligent approach to brittleness index estimation in gas shale reservoirs: a case study from a western Iranian basin," Journal of Natural Gas Science and Engineering, vol. 44, pp. 177-190, 2017.

[11] K. Sato and T. Hashida, "Fracture toughness evaluation based on tension-softening model and its application to hydraulic fracturing," Pure and Applied Geophysics, vol. 163, pp. 10731089, 2006.

[12] L. Huang, J. Liu, F. Zhang, E. Dontsov, and B. Damjanac, "Exploring the influence of rock inherent heterogeneity and grain size on hydraulic fracturing using discrete element modeling," International Journal of Solids and Structures, vol. 176-177, pp. 207-220, 2019.

[13] J. Li, X. Li, H. Zhan et al., "Modified method for fracability evaluation of tight sandstones based on interval transit time," Petroleum Science, vol. 17, pp. 477-486, 2020.

[14] A. Suboyin, M. M. Rahman, and M. Haioun, "Hydraulic fracturing design considerations, water management challenges and insights for Middle Eastern shale gas reservoirs," Energy Reports, vol. 6, pp. 745-760, 2020.

[15] F. Zhang, B. Damjanac, and S. Maxwell, "Investigating hydraulic fracturing complexity in naturally fractured rock masses using fully coupled multiscale numerical modeling," Rock Mechanics and Rock Engineering, vol. 52, no. 12, pp. 51375160, 2019.

[16] O. R. Barani, N. G. Haghighat, and P. Salmani, "Detailed description of the geomechanical interaction between a cohesive hydraulic fracture and a natural fracture in saturated poroelastic media," Geotechnical and Geological Engineering, vol. 38, no. 2, pp. 1689-1705, 2020. 
[17] E. C. M. Sanchez, J. A. R. C. Msc, and D. Roehl, "Numerical simulation of three-dimensional fracture interaction," Computers and Geotechnics, vol. 122, p. 103528, 2020.

[18] S. E. Saberhosseini, R. Keshavarzi, and K. Ahangari, "A new geomechanical approach to investigate the role of in-situ stresses and pore pressure on hydraulic fracture pressure profile in vertical and horizontal oil wells," Geomechanics and Engineering, vol. 7, no. 3, pp. 233-246, 2014.

[19] H. Zhu, J. Deng, S. Liu et al., "Hydraulic fracturing experiments of highly deviated well with oriented perforation technique," Geomechanics and Engineering, vol. 6, no. 2, pp. 153172, 2014.

[20] C. Yan, X. Ren, Y. Cheng et al., "An experimental study on the hydraulic fracturing of radial horizontal wells," Geomechanics and Engineering, vol. 17, no. 6, pp. 535-541, 2019.

[21] R. Rabbel, K. Mair, O. Galland, C. Grühser, and T. Meier, "Numerical modeling of fracture network evolution in organic - rich shale with rapid internal fluid generation," JGR Solid Earth, vol. 125, article e2020JB019445, 2020.

[22] X. Liu, W. Zhang, Z. Qu et al., "Feasibility evaluation of hydraulic fracturing in hydrate-bearing sediments based on analytic hierarchy process-entropy method (AHP-EM)," Journal of Natural Gas Science and Engineering, vol. 81, p. 103434, 2020.

[23] E. Fjaer, R. M. Holt, P. Hordrud, A. M. Raaen, and R. Risnes, Petroleum Related Rock Mechanic, Elsevier, Kidlington, Oxford, UK, 2008.

[24] R. Gholami, M. Rabiei, V. Rasouli, B. Aadnoy, and N. Fakhari, "Application of quantitative risk assessment in wellbore stability analysis," Journal of Petroleum Science and Engineering, vol. 135, pp. 185-200, 2015.

[25] L. Obert and W. I. Duvall, Rock Mechanics and the Design of Fractures in Rock, John Wiley \& Sons, New York, NY, USA, 1967.

[26] J. C. Jaeger, N. G. W. Cook, and R. W. Zimmerman, Fundamentals of Rock Mechanics, Blackwell Publ, London, UK, 2007.

[27] E. Kias, R. Maharidge, and R. Hurt, "Mechanical versus mineralogical brittleness indices across various shale plays," in SPE Annual Technical Conference and Exhibition Held, Houston, Texas, USA, 2015.

[28] X. B. Wang, "Analysis of plastic deformation and fracture energy of rock specimen in uniaxial compression," Chinese Journal of Rock Mechanics and Engineering, vol. 24, no. 10, pp. 1735-1739, 2005.

[29] M. Beynon, "DS/AHP method: a mathematical analysis, including an understanding of uncertainty," European Journal of Operational Research, vol. 140, no. 1, pp. 148-164, 2002.

[30] R. Nagpal, D. Mehrotra, and P. Bhatia, "Usability evaluation of website using combined weighted method: fuzzy AHP and entropy approach," International Journal of Systems Assurance Engineering and Management, vol. 7, no. 4, pp. 408-417, 2016.

[31] S. Shapiro, C. Dinske, and E. Rothert, "Hydraulic-fracturing controlled dynamics of microseismic clouds," Geophysical Research Letters, vol. 33, no. 14, article L14312, 2006.

[32] S. Shi, Z. Liu, J. Feng, G. Feng, and M. Li, "Using 3D seismic exploration to detect ground fissure," Advances in GeoEnergy Research, vol. 4, no. 1, pp. 13-19, 2020. 